\title{
Genetically-Encoded Fluorescent Reporters of Histone Methylation in Living Cells
}

\author{
Chi-Wang Lin, Cindy Y. Jao, and Alice Y. Ting* \\ Department of Chemistry, Massachusetts Institute of Technology, \\ Cambridge, Massachusetts, 02139
}

\section{Supporting Information}

K9 Reporter

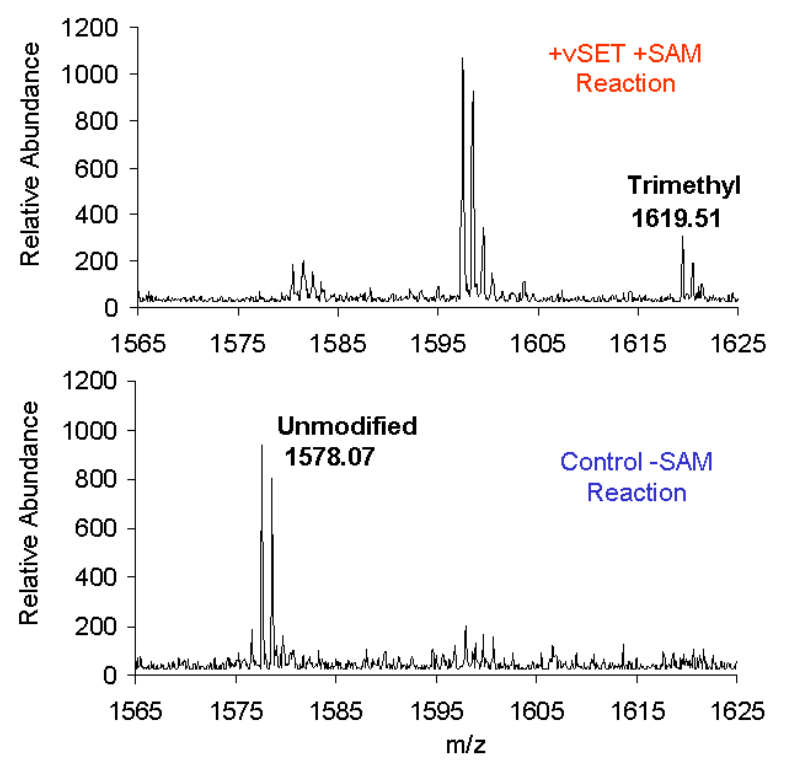

K27 Reporter
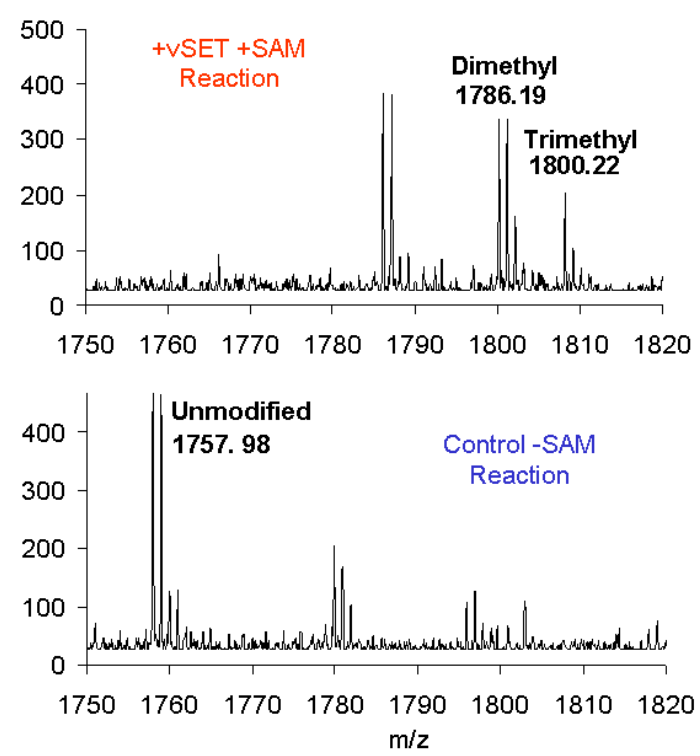

MALDI-TOF spectra of Glu-C digested reporters from the reactions in Figure 2a. Left: the +vSET/+SAM K9 reporter sample is cleanly trimethylated (GSARTAQTARK(Me) 3 STGGE, calc. 1619.85), while the -SAM control contains only unmodified reporter protein (GSARTAQTARKSTGGE, calc. 1577.80). Right: The methylation reaction with the $\mathrm{K} 27$ reporter contains both di- and trimethylated protein (GSARTAAARK(Me) $)_{2,3}$ SAPATGGVE, calc. 1785.96 and 1799.98), while the -SAM control contains only unmodified reporter protein (GSARTAAARKSAPATGGVE, calc. 1757.93).

\section{Experimental Protocols:}

1. Construction of the $\mathbf{K} 9$ reporter gene. An insert containing the HP1 chromodomain, linker, and substrate peptide was constructed through two successive PCR reactions. For the first PCR, the HP1 gene (a gift from Sepideh Khorasanizadeh) was used as the template, and the primers HP1.F (5'-ACCGCCGCCCGCATGCATGAGGAGGAGTACGCCGT; incorporates a SphI site) and HP1.R (5'-GCAGAACCCTCACCAGA- 
ACCCGGCTTCCCAGATCCAGATGTAGACCCATCCTTGCGGCTCGCCTCGTAC; incorporates the linker and part of the substrate peptide) were used for the amplification. For the second PCR, the product of the first PCR reaction was used as the template and the primers HP1.F and H3K9.R (5'- CCATGAGCTCGCCGCCGGTAGACTTGCGAGCTGTCTGGGCCGTCCGGGCAGAACCCTCACC; incorporates the rest of the substrate peptide and a $\mathrm{SacI}$ site) were used for the amplification. The insert was digested with SphI and SacI and ligated in-frame into similarly-digested EGFR reporter pRSETB plasmid (GenBank accession number AF440201). The EGFR reporter pRSETB plasmid contains a CFP gene immediately upstream from the unique SphI site, and a YFP gene immediately downstream from the unique SacI site.

2. Construction of the K27 reporter gene. An insert containing the Polycomb ( $\mathrm{Pc})$ chromodomain, linker, and substrate peptide was constructed through two successive PCR reactions. For the first PCR, the Pc gene (a gift from Yi Zhang) was used as the template, and the primers Pc.F (5'- GCTGCTCGCATGCTCCCAGTCGATCTAGTGTAC; incorporates a SphI site) and Pc.R (5'- GGCAGAACCCTCACCAGAACCCGGCTTCCCAGATCCAGATGTAGACCCGGATTTGTTCGTTTG TTCGTAG; incorporates the linker and part of the substrate peptide) were used for the amplification. For the second PCR, the product of the first PCR reaction was used as the template and the primers Pc.F and H3K27.R (5'- CCATGAGCTCCACCCCCCCCGTAGCTGGAGCGCTTTTGCGCGCTGCGGCCGTCCGGGCAGAACC CTCACC; incorporates the rest of the substrate peptide and a SacI site) were used for the amplification. The insert was digested with SphI and SacI and ligated in-frame into similarly-digested EGFR reporter pRSETB plasmid (GenBank accession number AF440201). The EGFR reporter pRSETB plasmid contains a CFP gene immediately upstream from the unique $S p h I$ site, and a YFP gene immediately downstream from the unique SacI site.

3. Reporter expression and purification. pRSETB plasmid containing the reporter gene between $B a m \mathrm{HI}$ and EcoRI sites was introduced into the bacterial strain BL21(DE3) (Stratagene, La Jolla, CA) by heat-shock transformation. The cells were grown in Luria Broth supplemented with ampicillin $(100 \mu \mathrm{g} / \mathrm{mL})$ at $37^{\circ} \mathrm{C}$ until $\mathrm{OD}_{600} 0.5$. Isopropyl $\beta-$ D-thiogalactopyranoside (IPTG) was added to a final concentration of $0.4 \mathrm{mM}$ to induce reporter protein expression. The cells were grown for 3 hours at $30^{\circ} \mathrm{C}$ and then harvested by centrifugation. Cells were lysed by sonication at $4{ }^{\circ} \mathrm{C}$ (six 30 -second pulses at halfmaximal power with 1 minute in between each pulse) in lysis buffer ( $50 \mathrm{mM}$ Tris $\mathrm{pH} 7.8$, $300 \mathrm{mM} \mathrm{NaCl}, 4 \mathrm{mM}$ PMSF, and 1/4 EDTA-free protease inhibitor cocktail tablet (Roche, Indianapolis, IN) per $10 \mathrm{~mL}$ of lysis buffer). The His 6 -tagged reporter was purified from the lysate using a Ni-NTA agarose column (Qiagen, Valencia, CA) following the manufacturer's suggested protocol. Fractions containing the reporter were consolidated and transferred into TBS $(140 \mathrm{mM} \mathrm{NaCl}, 3 \mathrm{mM} \mathrm{KCl}, 25 \mathrm{mM}$ Tris $\mathrm{pH}$ 7.4) by two rounds of dialysis for storage in aliquots at $-80^{\circ} \mathrm{C}$. Typical yields were $100-500 \mu \mathrm{g}$ of protein per $0.5 \mathrm{~L}$ culture.

4. vSET expression and purification. The vSET expression plasmid (Paramecium bursaria chlorella virus SET domain in pET22b (Novagen, Madison, WI)) was a kind 
gift from Ming-Ming Zhou. The plasmid was introduced into the bacterial strain BL21(DE3) (Stratagene, La Jolla, CA) by heat-stock transformation. The cells were grown in Luria Broth supplemented with ampicillin $(100 \mu \mathrm{g} / \mathrm{mL})$ at $37^{\circ} \mathrm{C}$ until $\mathrm{OD}_{600}$ 0.5 . Isopropyl- $\beta$-D-thiogalactopyranoside (IPTG) was added to a final concentration of $0.4 \mathrm{mM}$ to induce enzyme expression. The cells were grown for 3 hours at $30{ }^{\circ} \mathrm{C}$ and then harvested by centrifugation. Cells were lysed by sonication at $4{ }^{\circ} \mathrm{C}$ ( $\operatorname{six} 30$-second pulses at half-maximal power with 1 minute in between each pulse) in lysis buffer (50 $\mathrm{mM}$ Tris $\mathrm{pH}$ 7.8, $300 \mathrm{mM} \mathrm{NaCl}, 4 \mathrm{mM}$ PMSF, and 1/4 EDTA-free protease inhibitor cocktail tablet (Roche, Indianapolis, IN) per $10 \mathrm{~mL}$ of lysis buffer). The His 6 -tagged protein was purified from the lysate using a Ni-NTA agarose column (Qiagen, Valencia, CA) following the manufacturer's suggested protocol. Fractions containing the protein were consolidated and transferred into storage buffer $(20 \mathrm{mM}$ Tris $\mathrm{pH} 8.0,500 \mathrm{mM} \mathrm{NaCl}, 500$ $\mathrm{mM}$ urea) by two rounds of dialysis for storage in aliquots at $-80^{\circ} \mathrm{C}$.

5. In vitro methylation assays. Reaction conditions for the in vitro methylation assays were as follows: $5-10 \mu \mathrm{M}$ reporter protein, $2 \mathrm{mM} \mathrm{S}$-adenosylmethionine (SAM), 20 $\mathrm{mM}$ Tris pH 8.0, $10 \mathrm{mM} \mathrm{MgCl}_{2}, 20 \mathrm{mM} \mathrm{KCl}, 0.5 \mathrm{mM} \mathrm{H}_{2} \mathrm{SO}_{4}, 0.5 \mathrm{mM}$ DTT, and 0.3-0.5 $\mu \mathrm{g} / \mu \mathrm{L}$ of vSET enzyme. Reactions were incubated at $30^{\circ} \mathrm{C}$ for the indicated times.

6. Endoproteinase Glu-C digestion and MALDI analysis of methylated reporters. The K9 and K27 reporters were enzymatically methylated as described above (5). After a reaction time of 10 hours, the reporters were digested by adding $1.5 \mu \mathrm{g}$ of endoproteinase Glu-C enzyme (Sigma, Allentown, PA) to $35 \mu \mathrm{L}$ of methylated reporter solution. The reaction was incubated at $37^{\circ} \mathrm{C}$ for 16 hours, then combined in a $1: 1(\mathrm{v} / \mathrm{v})$ ratio with a solution of saturated $\alpha$-cyano-4-hydroxycinnamic acid in $0.1 \%$ trifluoroacetic acid with $50 \%$ acetonitrile. $1 \mu \mathrm{L}$ of this mixture was loaded onto the MALDI target. Positive-ion MALDI-TOF data was collected in the MIT Chemistry Department facility in reflection mode with external calibration.

7. Cell imaging. pCDNA3 (Invitrogen, Carlsbad, CA) plasmid containing the reporter gene between the BamHI and EcoRI sites was introduced into mouse embryonic fibroblasts (wild-type and Suv39h -/- cells both from Thomas Jenuwein) by transfection with Fugene 6 (Roche, Indianapolis, IN). Images were collected 12-24 hours after transfection on a Zeiss Axiovert 200M inverted epifluorescence microscope with differential interference contrast (DIC). Cells were maintained in $10 \%$ fetal bovine serum in phenol red-free DMEM (Invitrogen, Carlsbad, CA) at $37{ }^{\circ} \mathrm{C}$ under $5 \% \mathrm{CO}_{2}$ during imaging with an environmental control system that housed the microscope stage. For each sample, four images were collected in rapid succession (automated using OpenLab software (Improvision, Lexington, MA)): a CFP image (420DF20 excitation, 450DRLP dichroic, 475DF40 emission), a FRET image (420DF20 excitation, 450DRLP dichroic, 530DF30 emission), a YFP image (495DF10 excitation, 515DRLP dichroic, 530DF30 emission), and a DIC image (775DF50 emission). Fluorescence images were backgroundcorrected. Acquisition times were in the range of 100 to 800 milliseconds. The emission ratio image was generated by dividing the FRET image by the CFP image. The images shown in Figure 3 represent merges between the emission ratio images and the DIC images. 